\title{
A homeo domain protein lacking specific side chains of helix 3 can still bind DNA and direct transcriptional repression
}

\author{
Andrew K. Vershon, ${ }^{1,2,3}$ Yisheng Jin, ${ }^{1}$ and Alexander D. Johnson ${ }^{2}$ \\ ${ }^{1}$ Waksman Institute and Department of Molecular Biology and Biochemistry, Rutgers University, Piscataway, New Jersey \\ 08855 USA; $^{2}$ Department of Microbiology and Immunology, University of California at San Francisco, San Francisco, \\ California 94143 USA
}

\begin{abstract}
A series of mutations in the homeo domain of the yeast $\alpha 2$ protein were constructed to test, both in vivo and in vitro, predictions based on the $\alpha 2-D N A$ cocrystal structure described by Wolberger et al. (1991). The effects of the mutations were observed in three different contexts using authentic target DNA sequences: $\alpha 2$ binding alone to specific DNA, $\alpha 2$ binding cooperatively with MCM1 to specific DNA, and $\alpha 2$ binding cooperatively with a1 to specific DNA. As expected, changes in the amino acid residues that contact DNA in the X-ray structure severely compromised the ability of $\alpha 2$ to bind DNA alone and to bind DNA cooperatively with MCM1. In contrast, many of these same mutations, including a triple change that altered all the "recognition" residues of helix 3, had little or no effect on the cooperative binding of $\alpha 2$ and a1 to specific DNA, as determined both in vivo and in vitro. These results show that the ability of a homeo domain protein to correctly select and repress target genes does not necessarily depend on the residues commonly implicated in sequence-specific DNA binding.
\end{abstract}

[Key Words: Homeo domain proteins; DNA-binding specificity; combinatorial control]

Received August 16, 1994; revised version accepted November 30, 1994.

The yeast $\alpha 2$ protein is a member of the homeo domain family of DNA-binding proteins; this highly conserved sequence motif was first recognized in several genes that control development in Drosophila (Laughon and Scott 1984; McGinnis et al. 1984a,b; Shepherd et al. 1984). Homeo domain proteins have now been found in nearly all eukaryotic organisms, ranging from yeast to humans, and several hundred members of this DNA-binding family are known (for review, see Scott et al. 1989; Hayashi and Scott 1990; Wuthrich and Gehring 1992). The structures of five different homeo domains, including that of $\alpha 2$, have been determined by nuclear magnetic resonance (NMR) spectroscopy or X-ray crystallography (Qian et al. 1989; Kissinger et al. 1990; Otting et al. 1990; Phillips et al. 1991; Wolberger et al. 1991; Billeter et al. 1993; Ceska et al. 1993; Leiting et al. 1993; Klemm et al. 1994). Despite limited sequence identity among these homeo domains, they adopt nearly the same conformation. The mechanism of DNA binding also appears to be remarkably similar in that most of the DNA backbone and some of the base-specific contacts are identical in the structures of the homeo domains bound to DNA.

The X-ray and NMR structures provide a clear picture of how homeo domain proteins bind to DNA on their own. We wished to test whether predictions from these

\footnotetext{
${ }^{3}$ Corresponding author.
}

structures hold when a homeo domain binds DNA cooperatively with other proteins. The yeast $\alpha 2$ protein provides a number of advantages for this analysis. (1) The target genes and the "other" proteins are known. In $\alpha$ cells, $\alpha 2$ binds DNA cooperatively with MCM1 to turn off transcription of the a-specific genes. The 32-bp DNA sequence recognized jointly by a dimer of $\alpha 2$ and a dimer of MCMl is called the a-specific gene (asg) operator (Johnson and Herskowitz 1985; Keleher et al. 1988; Passmore et al. 1989; Ammerer 1990; Smith and Johnson 1992). In a $/ \alpha$ cells, $\alpha 2$ performs a second function: It binds cooperatively (as a heterodimer) with the homeo domain protein al to a second type of operator, the hsg operator, to turn off the haploid-specific genes (Strathern et al. 1981; Miller et al. 1985; Goutte and Johnson 1988, 1993, 1994; Dranginis 1990). (2) $\alpha 2$, a 1, and MCM1 have all been purified, and their DNA-binding properties have been characterized extensively (see above references). (3) The structure of the $\alpha 2$ homeo domain complexed with a biologically relevant DNA sequence la variant of the asg operator) has been determined (Wolberger et al. 1991). (4) A series of asg operator- and hsg operator-containing reporter constructs have been described which, when combined with the relative ease of yeast genetics, provide a simple, quantitative way to test the effect of $\alpha 2$ mutations in vivo (Goutte and Johnson 1988; Keleher et al. 1988; Mak and Johnson 1993). 
Based on the X-ray and NMR structures, we constructed a series of point mutations predicted to damage the DNA-binding affinity of $\alpha 2$ and tested the effects of the mutations in vitro and in vivo. Although most of the changes that we examined destroyed the ability of $\alpha 2$ to work alone and in combination with MCM1, to our surprise, most of the mutant $\alpha 2 \mathrm{~s}$ still functioned in combination with al. We conclude that many of the specific side chains of $\alpha 2$ that contact DNA in the $\alpha 2 / D N A$ $\mathrm{X}$-ray structure are not required for DNA binding of $\alpha 2$ in conjunction with al.

\section{Results}

Point mutations in the homeo domain of $\alpha 2$ reduce the level of $\alpha 2 / M C M 1$ repression in vivo

As described in Materials and methods, we developed a scheme to construct site-specific mutations in the $\alpha 2$ gene, to introduce these mutations into yeast for in vivo repression analysis, and to introduce the mutations into bacterial expression vectors to provide a source of pure protein for DNA-binding experiments.

The $\alpha 2$ protein is 210 residues in length and contains two stable domains (Sauer et al. 1988). The homeo domain is part of the carboxy-terminal domain, and NMR and crystallography experiments have shown that this region forms three $\alpha$-helices that pack into a tight bundle (Phillips et al. 1991; Wolberger et al. 1991). A sketch of the $\alpha 2$ homeo domain bound to its DNA site is shown in Figure 1. The first helix (residues 138-150 of the intact protein) and the second helix (residues 159-169) pack against each other in a roughly antiparallel fashion, and both of these pack against the third helix, which lies across them. The third helix (residues 173-189), frequently termed the "recognition helix," lies in the major groove of the DNA and makes three base-specific contacts and a series of sugar-phosphate backbone contacts. An extended region at the beginning of the $\alpha 2$ homeo domain (the amino-terminal arm), which lies in the minor groove of the DNA, appears to make at least one base-specific contact. Immediately following the carboxyl terminus of the homeo domain is a 20 -amino-acid tail that does not contact DNA but is required for interaction with al (Strathern et al. 1988; Mak and Johnson 1993).

A list of the point mutations that we constructed in the $\alpha 2$ homeo domain and their effects on $\alpha 2 / \mathrm{MCM} 1$ mediated repression are shown in Figure 2. For these experiments, the mutant $\alpha 2$ proteins were expressed from the $\alpha 2$ promoter carried on a CEN plasmid, and their activities were monitored using an asg operator reporter construct that was integrated into the yeast genome. In most cases, the results of mutations in the homeo domain agree well with predictions made from the crystal structure. For example, Arg-173, Gln-175, Lys-186, and Lys-188 all make contacts with the DNA phosphate backbone, and point mutations in any of these residues have a large deleterious effect on the level of $\alpha 2 /$ MCM1-mediated repression.

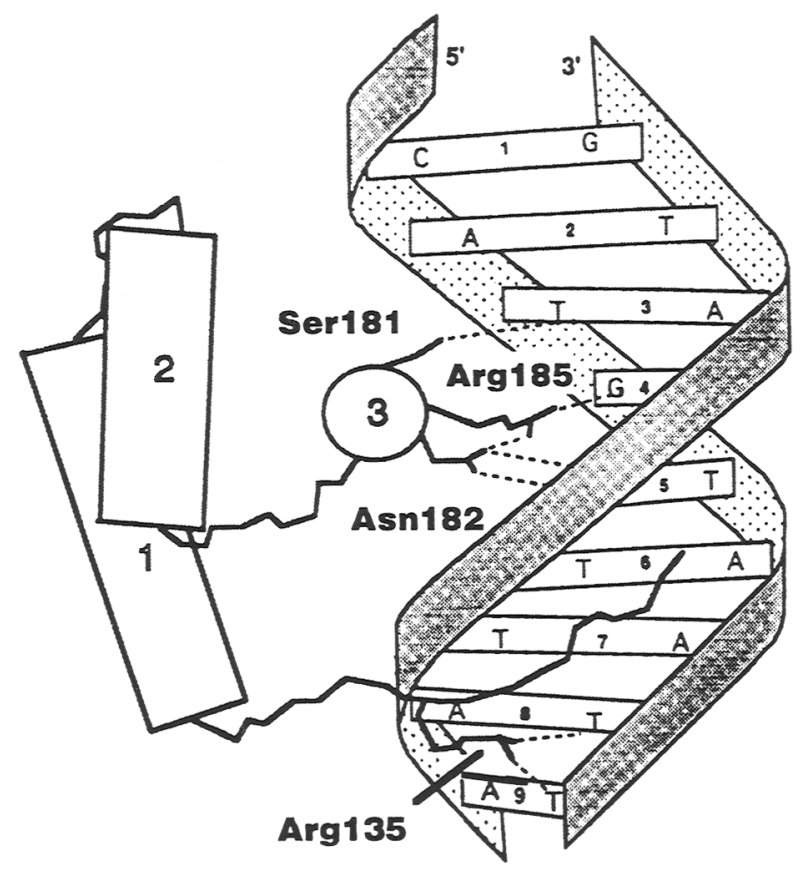

Figure 1. A sketch summarizing the base-specific contacts observed in the crystal structure of $\alpha 2$ complexed with specific DNA. The diagram is based on the crystal structure derived from Wolberger et al. (1991). Base-specific contacts in the major groove (Ser-181, Asn-182, and Arg-185) and minor groove (Arg135 ) of the DNA are also shown. The DNA shown is the halfsite from the asg operator.

Amino acid substitutions in residues that make major groove base-specific contacts in the X-ray crystal structure, Ser-181, Asn-182, and Arg-185, also have large damaging effects on the level of repression. This result confirms that all of these residues play major roles in the recognition of the DNA. The Ser-181-Gln mutation is noteworthy in that this position has been studied extensively in other homeo domain proteins, and, for some cases, it has been proposed to be a major determinant of DNA-binding specificity (Hanes and Brent 1989; Treisman et al. 1989; Schier and Gehring 1993). In the $\alpha 2$ $\mathrm{X}$-ray structure, this side chain has been modeled to make an extended van der Waals contact with the third position in the major groove of the operator (Wolberger et al. 1991). The GIn substitution, which inserts a larger, bulkier side chain in place of Ser-181, does not have as large deleterious effect on the level of repression as might be expected if this residue provides a critical determinant of DNA-binding specificity. In the engrailed homeo domain cocrystal structure, the Gln residue at the homologous position contacts the second position of the operator (Kissinger et al. 1990). A substitution of this residue from Gln to Ala had only a small effect on its DNA-binding activity, suggesting that the Gln at this position may only play a small role in determining the engrailed DNA-binding affinity and specificity (Ades and Sauer 1994). One explanation for the partial repression by the $\alpha 2$ Ser-181-Gln mutant is that the Gln side chain 
Figure 2. In vivo assays for transcriptional repression by $\alpha 2 /$ $\mathrm{MCM} 1$ and al $/ \alpha 2$. (A) Assay for a-specific gene repression by $\alpha 2$ mutants. Plasmid pAV115, a CEN LEU2 plasmid, containing the entire $M A T \alpha$ locus with a specific site-directed mutation in the $\alpha 2$ gene ( $\alpha 2^{\star}$ here), was transformed into a mat $\Delta$ strain containing an integrated copy of a derivative of $\mathrm{pSJ} 3$, an asg reporter, at the URA3 locus on chromosome V. $\alpha 2 / \mathrm{MCM} 1$-mediated repression was monitored by measuring the $\beta$-galactosidase produced from a CYC1-lacZ promoter that contains an $\alpha 2 / M C M 1$ operator site. The MCMl protein was expressed from its endogenous gene on chromosome XIII. Nonrepressed conditions /tester strain transformed with pAV114, a blank control vector) produced an average $150 \pm 10$ units of $\beta$-galactosidase activity. Full repression of the reporter promoter (tester strain transformed with pAV115 containing a wild-type copy of $\alpha 2$ ), gave an average of $6 \pm 1$ units of $\beta$-galactosidase activity, giving $\sim 22$-fold repression of the reporter promoter. $|B|$ Assay for haploid-specific gene repression of $\alpha 2$ mutants. al / $\alpha 2$-mediated repression by the $\alpha 2$ mutants was measured by a similar strategy using a MATa tester strain that contains an integrated copy of the CYC1-lacZ promoter containing an hsg operator. The al protein was expressed from its endogenous gene at the MAT locus on chromosome III. The presence of wild-type $\alpha 2$ in this tester strain repressed lac $Z$ expression from 30 units (pAV114) to 3 units (pAV115 wild-type $\alpha 2$ ), a 10-fold repression of the promoter construct. $(C)$ The effects of site-directed mutations in $\alpha 2$ on $\alpha 2 / \mathrm{MCM} 1-$ and al/ $\alpha 2$-mediated repression. The percent activity of each mutant relative to wild-type levels is shown. The calculations are based on the average of at least three independent transformants of each mutant.

may be repositioned so that it contacts the second position of the operator instead of the third base pair.

The NMR and X-ray homeo domain structures show that the amino-terminal region of the homeo domain wraps partially around the DNA to make contacts in the minor groove (Kissinger et al. 1990; Otting et al. 1990; Wolberger et al. 1991; Billeter et al. 1993; Klemm et al. 1994). In the engrailed structure, Arg side chains at the third and fifth positions of the homeo domain contact thymines at two adjacent base pairs. Residues at the third and fifth positions of other homeo domains are mostly Arg, suggesting that these contacts with the DNA are conserved and are important in binding affinity and specificity. The $\alpha 2$ homeo domain contains two Arg residues at the fourth (Arg-132) and seventh (Arg-135) positions instead of the third and fifth positions as in other homeo domain proteins. In the $\alpha 2$ cocrystal structure, residues Arg-132-Thr-137 lie in the minor groove; but only the Arg-135 side chain is well defined and is modeled to contact two adjacent base pairs (Wolberger et al. 1991). The large deleterious effect of the Arg135-Ala mutation indicates that Arg-135 is important for repression and DNA binding. The other arginine in the aminoterminal arm, Arg-132, appears to have only a minor role. The lack of a second additional DNA contact made by the amino-terminal arm may suggest why the DNAbinding affinity of $\alpha 2$ is intrinsically relatively low and why it requires accessory proteins to bind DNA with high affinity and specificity.

Mutations in side chains that lie close to the DNA but

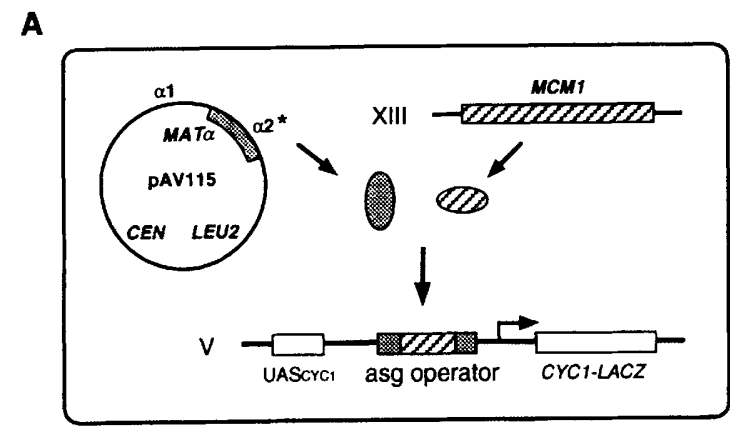

$\mathbf{B}$

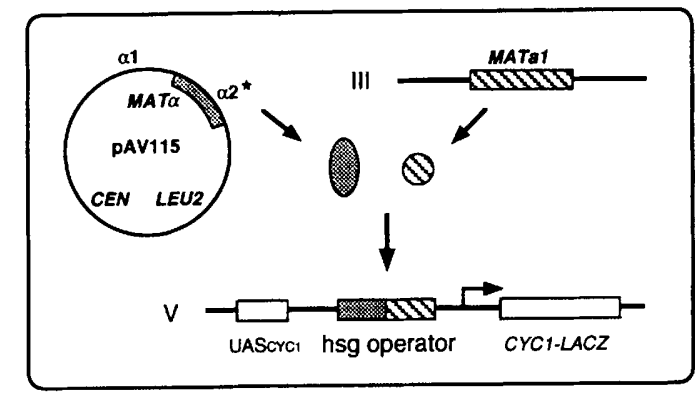

C

\begin{tabular}{|c|c|c|c|}
\hline & & $\begin{array}{l}\text { Repression with } \\
\text { MCM1 }\end{array}$ & $\begin{array}{c}\text { Repression with } \\
\text { a1 }\end{array}$ \\
\hline & Wild Type & $100 \%$ & $100 \%$ \\
\hline \multirow[t]{2}{*}{ N "Arm" } & $\mathrm{R} 132 \mathrm{~A}$ & 32 & 70 \\
\hline & R135A & 5 & 100 \\
\hline \multirow[t]{2}{*}{ Helix 2} & N164A & 64 & 90 \\
\hline & $\mathrm{K} 167 \mathrm{~A}$ & 91 & 90 \\
\hline \multirow[t]{13}{*}{ Helix 3} & R173A & 18 & 90 \\
\hline & $1174 \mathrm{~A}$ & 45 & 100 \\
\hline & Q175A & 5 & 70 \\
\hline & $\mathrm{K} 177 \mathrm{~A}$ & 23 & 90 \\
\hline & N178A & 9 & 70 \\
\hline & N178I & 9 & 40 \\
\hline & S181I & 9 & 100 \\
\hline & $S 181 Q$ & 23 & 90 \\
\hline & N182A & 9 & 80 \\
\hline & R185M & 5 & 90 \\
\hline & $\mathrm{K} 186 \mathrm{~N}$ & 5 & 110 \\
\hline & K188I & 5 & 90 \\
\hline & H3-3A & 5 & 60 \\
\hline C "Tail" & L196S & 100 & 5 \\
\hline
\end{tabular}

that do not appear to make a direct contact, such as Lys-177 and Asn-178, reduce the level of repression 5- to 10 -fold, suggesting that these side chains may also play a role in binding when $\alpha 2$ is bound in complex with MCM1. In the $\alpha 2$ cocrystal structure, Asn-178 lies in the major groove, but it does not appear to make any basespecific or phosphate-backbone contacts. One substitution at this position, Asn-178-Ile, introduces a larger side chain, and it is likely that it interferes with DNA binding. The other mutant, Asn-178-Ala, is harder to 
reconcile with the crystal structure because the substitution effectively removes the side chain. It is possible that Asn-178 is involved in contacting the DNA through a water-mediated hydrogen bond (Gehring et al. 1994) and that a substitution of this side chain with alanine would remove this contact (C. Wolberger, pers. comm.).

Mutations in other solvent-exposed residues that are distal from the DNA, such as residues Asn-164 and Asn167, which lie on the back side of the homeo domain in helix 2, have little or no effect on the level of repression and serve as convenient controls. Altogether, these results show that $\alpha 2$ side chains that make contacts with the DNA in the cocrystal structure are required for efficient repression with MCMl in vivo.

\section{Point mutations in the homeo domain of $\alpha 2$ do not reduce the level of $a 1 / \alpha 2$ repression in vivo}

The effect of the $\alpha 2$ mutations on al $/ \alpha 2$-mediated repression was tested in a similar way using an integrated hsg-operator reporter, with al being supplied from a chromosomal copy of MATa (Fig. 2B). We found that most of the $\alpha 2$ mutants that completely destroy $\alpha 2$ / MCM1-mediated repression (above) have little or no effect on a $1 / \alpha 2$-mediated repression. Even amino acid substitutions with large damaging effects on $\alpha 2 / \mathrm{MCM} 1$-mediated repression and predicted by the crystal structure to affect key protein-DNA contacts (e.g., Lys-188-Ile or Arg-185-Met) function at nearly wild-type levels with a1.

As a control for this experiment, we constructed a point mutation in $\alpha 2$ (Leu-196-Ser) that was shown previously to abolish al $/ \alpha 2$-mediated repression of haploidspecific genes but not $\alpha 2 /$ MCM1-mediated repression of the a-specific genes (Strathern et al. 1988). Residue Leu196 lies in the carboxy-terminal tail region adjacent to the homeo domain, and deletion analysis of the $\alpha 2$ protein has established that this tail region is important for cooperative DNA binding between al and $\alpha 2$ (Mak and Johnson 1993). In accordance with the previous analysis of this mutant, it retains the ability to repress transcription with MCM1 at roughly wild-type levels but fails to repress transcription with the al protein (Fig. 2). This result serves as a control and indicates that the observed repression of the al $/ \alpha 2$ operator site by the $\alpha 2$ mutants that we constructed is not the result of a failure of our assays to detect a loss of repression.

One possible interpretation of these results is that the levels of al and $\alpha 2$ proteins in the cell are sufficiently high to enable them to bind to the al/ 2 site, even though the protein-DNA interactions have been substantially weakened. Mutations in a single side chain that contacts the DNA might therefore have a small but undetectable effect on the level of repression. To test this model, a triple mutant-Ser-181-Ala/Asn-182-Ala/ Arg-185-Ala, referred to as $\mathrm{H} 3-3 \mathrm{~A}-$ that removes all three side chains that make base-specific contacts in the major groove of the DNA was constructed. As expected, this mutant was completely defective in repressing transcription with MCMl; however, it still showed signifi- cant levels of repression with al (Fig. 2C). We conclude from these results that when in a complex with al, these residues are not crucial for repression in the cell.

\section{Integration of $\alpha 2$ mutants into the chromosomal MAT locus}

In the experiments described above, the $\alpha 2$ protein was expressed from its endogenous promoter on a low copy $C E N$ plasmid. To rule out complications resulting from plasmid loss or overexpression, we constructed stable chromosomal copies of the $\alpha 2$ mutations at the MAT locus (see Materials and methods). $\alpha$ Cells carrying the mutant $\alpha 2$ (mat 2 cells) were tested for repression of an asg reporter, and $M A T \alpha /$ mata 2 cells were tested for repression of an hsg reporter. The results are shown in Figure 3, and, in general, agree with those utilizing CEN plasmids. A couple of the mutants, such as Ser-181-Ile, and Arg-185-Met, show a larger effect on a1/ 22 -mediated repression than in the experiments utilizing CEN plasmids, and the amino-terminal arm mutant (Arg-135Ala) also appears to partially affect a1/ 2 -mediated repression. However, the most striking result is still exemplified by the phenotype of the triple mutant H3-3A: complete disruption of $\alpha 2 / \mathrm{MCM} 1$-mediated repression but wild-type levels of al/ $\alpha 2$-mediated repression.

Mutations in the $\alpha 2$ homeo domain destroy repression of endogenous a-specific genes but not endogenous haploid-specific genes

Although it seemed unlikely, it was formally possible that the reporters used in the experiments described above misrepresent the behavior of authentic a-specific and haploid-specific genes. To rule out this possibility, we tested the effects of the mutations on the repression of endogenous a- and haploid-specific genes using several bioassays. In general, these tests agree well with those utilizing the reporter constructs; a brief description of them follows (see also Materials and methods).

$\alpha$ Strains, each bearing a different mutant $\alpha 2$ integrated at the MAT locus (i.e., mat 2 strains), were assayed for their mating type (by testing their ability to mate with either MATa or MAT $\alpha$ tester strains) and for their production of a- and $\alpha$-mating factor (by the formation of halos on appropriate tester strains that are growth sensitive to mating factor) (Sprague 1991). In a cells, a strong mutation in the homeo domain, such as the triple mutant H3-3A, exhibits the same phenotype as a deletion of the $\alpha 2$ gene (Table 1). This mutant fails to repress a-specific genes, such as STE6 and BAR1, which allows the production of a-factor and the degradation of $\alpha$-factor, respectively. Thus, a mat $\alpha 2$ strain carrying the H3$3 \mathrm{~A}$ allele exhibits an a halo, whereas a wild-type $\alpha$ strain exhibits an $\alpha$ halo. This strain also fails to mate with either a or $\alpha$ cells, a phenotype characteristic of a mata2 deletion strain, because both a-specific and $\alpha$-specific genes are expressed (Strathern et al. 1981).

To test the effects of the $\alpha 2$ mutations on al/ $\alpha 2$-mediated repression of haploid-specific genes, we examined 

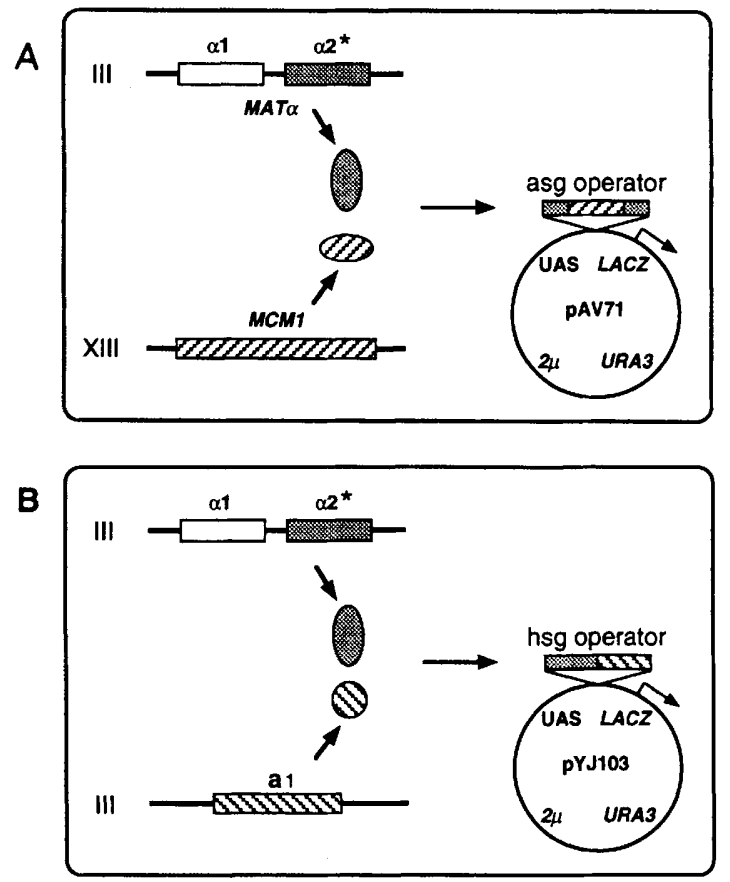

\begin{tabular}{|c|c|c|}
\hline & $\begin{array}{l}\text { Repression with } \\
\text { MCM1 in haploid }\end{array}$ & $\begin{array}{c}\text { Repression } \\
\text { a1 in diplo } \\
\end{array}$ \\
\hline MAT $\alpha 2$ & $100 \%$ & $100 \%$ \\
\hline$\Delta$ mata2 & 0 & 3 \\
\hline Wild Type & 100 & 100 \\
\hline R135A & 0 & 35 \\
\hline S181I & 1 & 20 \\
\hline S181Q & 2 & 100 \\
\hline R185M & 0 & 45 \\
\hline K188I & 2 & 100 \\
\hline H3-3A & 0 & 100 \\
\hline L196S & 100 & 2 \\
\hline
\end{tabular}

Figure 3. $\alpha 2 / \mathrm{MCM1}$ - and al/ $\alpha 2$-mediated repression by strains bearing integrated $\alpha 2$ mutations. $(A)$ Assay for a-specific gene repression of integrated $\alpha 2$ mutants. The mutant $\alpha 2$ genes expressed from their endogenous promoter were integrated at the MAT locus on chromosome III. The asg reporter construct is carried on plasmid pAV71. The expression from the reporter contstruct in a wild-type $\alpha 2$ strain is $1.2 \pm 0.1 \beta$-galactosidase units. The repression ratio was calculated by comparing the $\beta$-galactosidase values ( $155 \pm 8$ units) from the same strain transformed with a CYC1-lacZ plasmid without an asg operator (pAV73). (B) Assay for haploid-specific gene repression of integrated $\alpha 2$ mutants. a1/ $\alpha 2$-mediated repression is measured by the repression ratios of a diploid $M A T \mathbf{a} /$ mato 2 strain that is transformed with a CYC1-lacZ reporter plasmid containing an hsg operator site (pYJ103). In a wild-type MATa/MAT $\alpha$ background, this reporter produces $1.0 \pm 0.2 \beta$-galactosidase units. The repression ratio was calculated by comparing $\beta$-galactosidase values $(83 \pm 2$ units) from the same strains transformed with a reporter plasmid without an hsg operator (pAV73). (C) Repression ratios for the integrated $\alpha 2$ mutations in combination with MCM1 or with al. The level of repression by each mutant was calculated as a percent activity of wild-type $\alpha 2$ repression.
$M A T a / m a t \alpha 2$ strains for their production of a- or $\alpha$-factor and for their sporulation efficiency (Table 2). In these strains the $\alpha 2$ mutations that we constructed show two types of halo phenotypes that agree well with the results from the reporter constructs. One set of mutants, H3-3A, Ser-181-Gln, and Lys-188-Ile, produce small a halos on the tester strain. The presence of an a halo shows that these mutants fail to repress transcription of the a-specific genes (see above). The small halos indicate that only a low level of the a-factor is being expressed. The most plausible explanation for the decrease in mating-factor expression is that these $\alpha 2$ mutants are working in combination with the al protein to repress transcription of the haploid-specific gene STE12, which is required for full expression of the a-specific genes (Fields and Herskowitz 1985). This result agrees well with the results of the hsg reportors that show full repression in strains carrying these $\alpha 2$ mutations. The other set of mutants, exemplified by Ser-181-Ile, Arg-185-Met and Arg-135-Ala, produce a large a halo on the tester strains. All of these mutants show slightly reduced levels of repression of the hsg reporter; therefore, the most likely explanation for the larger halos is that these strains not only fail to repress a-specific genes but also allow sufficient expression of STE12 for a-specific gene activation.

We also examined the ability of the MATa/mata2 mutant strains to sponulate. We found that strains containing the wild-type $\alpha 2$, H3-3A, Ser-181-Gln, or Lys-188-Ile mutants are able to sporulate efficiently, showing that al $/ \alpha 2$-mediated repression is functional in all of these strains. However, strains that show a slight reduction in their ability to repress the hsg reporter fail to sporulate. The most likely explanation for this phenotype is that these mutants fail to completely repress the haploid-specific RME1 gene, a repressor of the meiotic pathway (Mitchell and Herskowitz 1986).

In conclusion, the tests for mating, mating pheromone production, and sporulation are in excellent agreement with the assays utilizing reporter constructs and provide an independent confirmation of the results.

\section{$\alpha 2$ homeo domain mutants fail to bind DNA on their own in vitro but still bind cooperatively with a1}

To examine directly the effects of the $\alpha 2$ point substitutions on DNA binding, the mutant proteins were expressed in Escherichia coli, purified to $>90 \%$ homogeneity, and assayed by electrophoretic mobility shift assays (Keleher et al. 1988; Sauer et al. 1988; Goutte and Johnson 1993). Wild-type intact $\alpha 2$ protein was compared with the same concentration of H3-3A, Arg-135Ala, Lys-188-Ile, and Leu-196-Ser mutant proteins in binding to the asg operator on their own and cooperatively with MCMl (Fig. 4A,B). The DNA-binding affinity of the H3-3A mutant protein appears to be at least 100fold lower than wild-type protein, a result expected because the mutant protein lacks all of the base-specific contacts that the homeo domain makes in the major groove of the DNA. Single amino acid substitutions in these three positions also significantly reduce the level 
Table 1. Mating-type and mating-factor production in $\alpha 2$ mutant strains

\begin{tabular}{|c|c|c|c|c|c|c|}
\hline \multirow[b]{2}{*}{ Strain } & \multirow[b]{2}{*}{ Genotype } & \multirow{2}{*}{$\begin{array}{l}\text { Repression of } \\
\text { asg reporter }(\%)\end{array}$} & \multicolumn{2}{|c|}{ Halo $^{a}$} & \multicolumn{2}{|c|}{ Mating } \\
\hline & & & $\mathbf{a}$ & $\alpha$ & with $M A T \alpha$ strain & with $M A T$ a strain \\
\hline 246.1.1 & $M A T \alpha$ & 100 & - & + & - & + \\
\hline EG123 & MATa & 0 & + & - & + & - \\
\hline $23 \alpha 182$ & $\Delta$ mat $\alpha 2$ & 0 & + & - & - & - \\
\hline YJ08 & wild type & 100 & - & + & - & + \\
\hline YJ05 & R135A & 0 & + & - & - & - \\
\hline YJ03 & S181I & 1 & + & - & - & - \\
\hline YJ07 & $\mathrm{S} 181 \mathrm{Q}$ & 2 & + & - & - & - \\
\hline YJ02 & R185M & 0 & + & - & - & - \\
\hline YJ06 & K188I & 2 & + & - & - & - \\
\hline Yj01 & $\mathrm{H} 3-3 \mathrm{~A}$ & 0 & + & - & - & - \\
\hline YJ04 & L196S & 100 & - & + & - & + \\
\hline
\end{tabular}

${ }^{a}(+)$ The strain forms a halo on the appropriate pheromone-sensitive tester strain.

$b_{\mid}+\mid 90-100 \%$ of wild-type mating efficiency; $(-\mid)$ less than a $0.1 \%$ efficiency.

of binding to the site on their own (data not shown). The affinity of Arg-135-Ala appears to be reduced by $\sim 50$ fold; this mutation removes the base-specific contact that the amino-terminal arm of the homeo domain makes in the minor groove of the DNA. The affinity of Lys-188-Ile, a mutant in a side chain that makes phosphate-backbone contact in the cocrystal structure, is also reduced by $\sim 50$-fold. These results indicate that the reduced level of repression in vivo is the result of the failure of $\alpha 2$ to bind to the operator site with wild-type affinity.

The wild-type and mutant $\alpha 2$ proteins were also tested for cooperative binding with al to the hsg operator (Fig. $4 \mathrm{C}$. The binding of the H3-3A, Arg-135-Ala, and Lys188-Ile mutant proteins are not detectably reduced from that of the wild-type protein. As a control, Leu-196-Ser is reduced at least 200 -fold in binding to the hsg operator with a1. Thus, the results obtained in vitro are consistent with our in vivo observations and confirm that the "base-specific" contacts between $\alpha 2$ and DNA are not crucial for the ability of $\alpha 2$ to act in combination with al.

\section{Discussion}

The homeo domain protein $\alpha 2$, a transcriptional repressor in yeast, acts in combination with two additional proteins: With MCM1, $\alpha 2$ turns off the a-specific genes; with al, $\alpha 2$ turns off the haploid-specific genes. The former combination occurs in $\alpha$ and $a / \alpha$ cells, and the latter occurs in the $a / \alpha$ cell only.

The X-ray structure of the $\alpha 2$ homeo domain complexed with a variant of the a-specific gene operator has been described (Wolberger et al. 1991), and we constructed a series of point mutations in the $\alpha 2$ homeo domain designed to impair base-specific and phosphatebackbone contacts without destabilizing the homeo domain structure. The analysis of these mutations leads to a surprising observation: Although nearly all of the mutations impaired the specific DNA binding of the $\alpha 2$ homeo domain on its own and impaired the combined action of $\alpha 2$ and MCM1, many of these same mutations had little or no effect on the cooperative binding of $\alpha 2$ and al to DNA. Moreover, many of these mutant $\alpha 2 \mathrm{~s}$ worked as efficiently in vivo as did wild-type $\alpha 2$ in re-

Table 2. Mating-factor production and sporulation efficiency in diploid $\alpha 2$ mutant strains

\begin{tabular}{|c|c|c|c|c|c|}
\hline \multirow[b]{2}{*}{ Strain } & \multirow[b]{2}{*}{ Genotype } & \multirow{2}{*}{$\begin{array}{l}\text { Repression of } \\
\text { hsg reporter }(\%)\end{array}$} & \multicolumn{2}{|c|}{$\mathrm{Halo}^{\mathrm{a}}$} & \multirow{2}{*}{$\begin{array}{l}\text { Sporulation } \\
\text { efficiency }(\%)\end{array}$} \\
\hline & & & $\mathbf{a}$ & $\alpha$ & \\
\hline $\mathrm{EG} 123 \times 246.1 .1$ & $\mathbf{a} / \alpha$ & 100 & - & + & 38 \\
\hline $\mathrm{EG} 123 \times 23 \mathrm{a} 182$ & $\mathbf{a} / \Delta m a t \alpha 2$ & 3 & + & - & $<0.1$ \\
\hline YI18 & $\mathrm{a} / \mathrm{WT}$ & 100 & - & - & 39 \\
\hline YJ15 & a/R135A & 35 & + & - & $<0.1$ \\
\hline YJ13 & $\mathbf{a} / \mathrm{S} 181 \mathrm{I}$ & 20 & + & - & $<0.1$ \\
\hline YJ17 & $\mathrm{a} / \mathrm{S} 181 \mathrm{Q}$ & 100 & $+1-$ & - & 11 \\
\hline YJ12 & $\mathrm{a} / \mathrm{R} 185 \mathrm{M}$ & 45 & + & - & $<0.1$ \\
\hline YJ16 & $\mathrm{a} / \mathrm{K} 188 \mathrm{I}$ & 100 & $+1-$ & - & 16 \\
\hline YJ1l & $\mathbf{a} / \mathrm{H} 3-3 \mathrm{~A}$ & 100 & $+1-$ & - & 20 \\
\hline YJ14 & a/L196S & 2 & - & + & $<0.1$ \\
\hline
\end{tabular}

a $+\mid$ That particular strain forms a halo on the appropriate pheromone-sensitive tester strain; $|+|-\mid$ A halo is formed on the tester strain, but it is significantly smaller than a normal halo. 
A

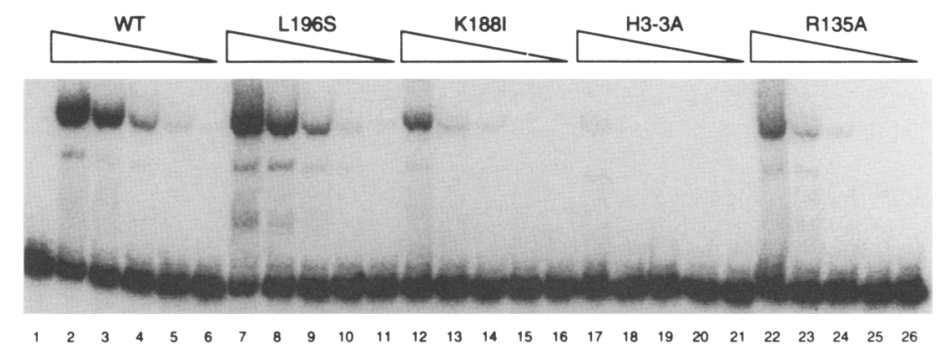

Figure 4. Mutations in the $\alpha 2$ homeo domain have reduced binding affinity to the asg operator with and without MCMl but have nearly wild-type binding affinity to the hsg operator in combination with al. $(A)$ Mobility retardation assay of the asg operator produced by decreasing concentrations of wild-type $\alpha 2$ (lanes 2-6), L196S (lanes 7-11), K188I (lanes 12-16), H3-3A (lanes 17-21), and R135A (lanes 22-26) mutant proteins in the absence of MCM1. The concentrations of $\alpha 2$ proteins are varied by fivefold dilutions from $4 \times 10^{-7} \mathrm{M}$ (lanes $2,7,12,17,22)$ to $6.4 \times 10^{-10} \mathrm{M}$ (lanes $\left.6,11,16,21,26\right)$. Free DNA is shown in lane 1 . (B) Mobility retardation assay to the asg operator produced by decreasing concentrations of wild-type $\alpha 2$ (lanes 3-7), L196S (lanes 8-12), K188I (lanes 13-17), H3-3A (lanes 18-22), and R135A (lanes 23-27) mutant proteins in the presence of a constant amount of MCM1 are shown. The concentrations of $\alpha 2$ proteins are varied by fivefold dilutions from $1.6 \times 10^{-8} \mathrm{M}$ (lanes $\left.3,8,13,18,23\right)$ to $2.5 \times 10^{-11} \mathrm{M}$ (lanes $7,12,17,22,27)$. Note that lane 4 in $A$ has the same concentration as lane 3 in $B$. Lane 2 shows the shift produced by MCM1 in the absence of $\alpha 2$, and lane 1 shows the free DNA. (C) Mobility retardation assay to the hsg operator produced by decreasing concentrations of wild-type (lanes 2-6), L196S (lanes 7-11), K188I (lanes 12-16), H3-3A (lanes 17-21), and R135A (lanes 22-26) $\alpha 2$ protein in the presence of a constant amount of al. The concentrations of $\alpha 2$ proteins are varied by fivefold dilutions from $4 \times 10^{-7} \mathrm{M}$ (lanes $\left.2,7,12,17,22\right)$ to $6.4 \times 10^{-10} \mathrm{M}$ (lanes $\left.6,11,16,21,26\right)$. The shifted band at the highest concentration of L196S (lane 7 ) is slightly higher than a normal al/ $\alpha 2$ shift and migrates at a position observed by a dimer of $\alpha 2$ binding alone to the site.

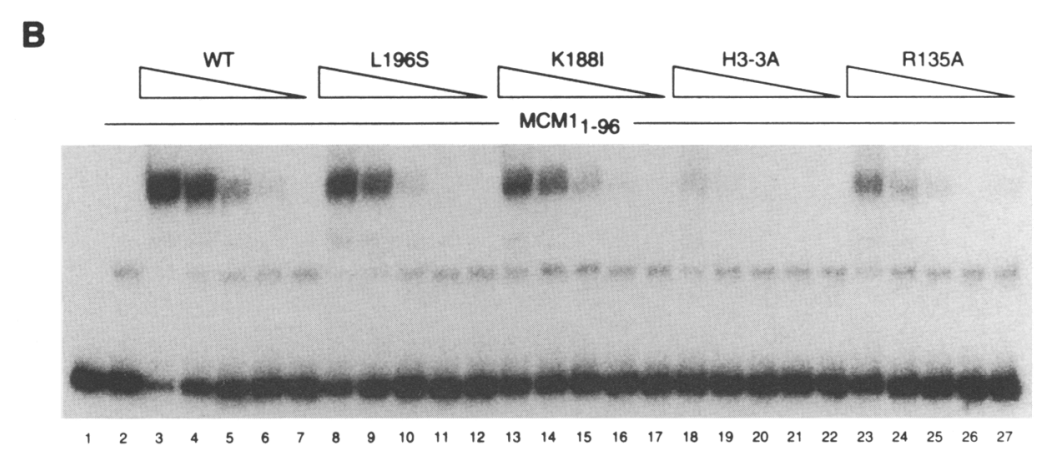

C

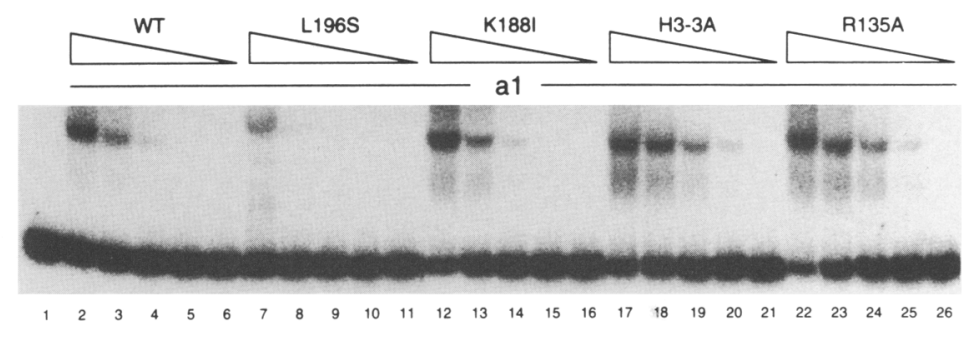

pressing transcription of the haploid genes in combination with al. Thus, when taken in combination with MCMI, the homeo domain mutations had the predicted effect; when taken with al, the mutations were largely silent. How can this "split phenotype" be explained? We consider four possibilities.

In theory, the simplest explanation would be that the $\alpha 2$ homeo domain does not contact DNA in the a1/ $\alpha 2-$ DNA complex. However, an extensive set of proteinDNA cross-linking experiments and chemical protection experiments has shown that the $\alpha 2$ homeo domain does contact DNA when bound with al (Goutte and Johnson 1993, 1994). Moreover, genetic and biochemical experiments have shown that the homeo domain of $\alpha 2$ is required for the DNA-binding activity of a $1 / \alpha 2$ (Porter and Smith 1986; Hall and Johnson 1987; Goutte and Johnson 1988).

A second possible explanation for the differential effects of the mutations is that $\alpha 2$ may contact DNA in two distinct ways: one in the $\alpha 2 / \mathrm{DNA}$ and $\alpha 2 / \mathrm{MCMl} /$ DNA complexes and the other in the al/ $\alpha 2 /$ DNA complex. According to this explanation, the point mutations would compromise the former but not the latter mode of DNA binding. Although it is difficult to rule out small differences in orientation, several lines of experiments suggest that $\alpha 2$ contacts DNA in roughly the same way in the three different complexes. First, chemical protection experiments show that the homeo domain of $\alpha 2$ makes a similar set of DNA contacts whether or not it is complexed with al (Goutte and Johnson 1994). Second, if the orientation of the $\alpha 2$ homeo domain was dramatically shifted in the al $/ \alpha 2$ complex, one would expect other surface-exposed residues of the homeo domain to contact DNA. However, we have shown that mutations of residues on the surface of helix 2 or the beginning of helix 3 had no effect on al $/ \alpha 2$ activity (Fig. 2C). Thus, it seems unlikely that $\alpha 2$ has two drastically different ways of contacting DNA. 
A third possibility is based on a model where al and $\alpha 2$ make equal contributions to the DNA-binding affinity and specificity of the heterodimer. According to this model, only half of the heterodimer-DNA contacts would be compromised by the $\alpha 2$ mutations, because al is still wild type. In contrast, because $\alpha 2$ binds as a dimer with MCM1, the $\alpha 2$ mutations would be expected to have a much more deleterious effect (roughly the square of the heterodimer affinity decrease). Although this argument must be true in principle, we feel that it cannot adequately explain the wild-type phenotype of the $\alpha 2$ mutants taken in combination with al. The binding of a dimeric protein /whether from prokaryotes or eukaryotes) to DNA is typically disrupted by the elimination of one set of monomer-DNA contacts. This applies to the binding of an $\alpha 2$ dimer with MCM1: The removal of one set of specific $\alpha 2-D N A$ contacts (by mutation of one-half of the operator) severely disrupts $\alpha 2 / \mathrm{MCM} 1$ repression in vivo (Smith and Johnson 1994). Thus, it seems unlikely that an a $1 / \alpha 2$ heterodimer could accommodate a loss of half (or nearly half) of its specific DNA contacts and still function in the cell.

A fourth possibility, and the one we favor, is that al provides the majority of the DNA-binding specificity for the heterodimer and that the constraints on $\alpha 2-$ DNA recognition are therefore loosened. Two additional observations are consistent with this idea: (1) When the known hsg operators are compared, the al halves of the site are conserved much more than are the $\alpha 2$ halves (Miller et al. 1985; Goutte and Johnson 1994). (2) Under a specific set of biochemical conditions, the specific/ nonspecific DNA-binding ratio is $\sim 30$ for the $\alpha 2$ dimer but $\sim 30,000$-fold for the al $/ \alpha 2$ heterodimer, again suggesting that al provides a large fraction of the specificity. (Because under the same conditions al does not bind DNA alone, we were unable to directly determine the al specificity ratio.) Therefore, we propose that in the al $/ \alpha 2$ DNA complex, al is providing the majority of the specific DNA contacts and the $\alpha 2 / D N A$ interface can tolerate changes in the residues that contact DNA without significantly compromising the ability of the heterodimer to recognize specific DNA in the cell. According to this model, the main role of $\alpha 2$ in the heterodimer would be to provide protein-protein contacts that convert al from a weak to a tight binding form.

Regardless of their precise molecular explanation, the results in this paper show that in one context lacting with MCM1) the $\alpha 2$ homeo domain is extremely sensitive to mutations that change residues responsible for sequence-specific binding. In another context (with al), the $\alpha 2$ homeo domain appears buffered, that is, relatively insensitive to these same changes. Other studies of homeo domain proteins have also revealed, in some in vivo contexts, a relative insensitivity to mutations in the DNA-binding residues. Porter and Smith (1986) analyzed in vivo a series of point mutations in the $\alpha 2$ homeo domain. These studies were carried out before structural information for homeo domains was available, and, viewed in retrospect, many of these changes probably destabilized the homeo domain structure and thereby inactivated both $\alpha 2 / \mathrm{MCM} 1$ and a1/ $\alpha 2$ repression in vivo. However, several mutations (Asn-178-His, Lys186-Asn, and Lys-188-Ile) showed a selective reduction in $\alpha 2 / \mathrm{MCM} 1$ repression, a result that anticipated some of the results presented in this paper. Another of their mutations, Asn-182-Asp, compromised $\alpha 2 / \mathrm{MCM} 1$ function as well as al/ $\alpha 2$ function in vivo, whereas a change of Asn-182 to Ala (Fig. 1C) inactivated only $\alpha 2 /$ MCMl function. In the crystal structure, the Asn-182 side chain contacts another side chain in helix 3 as well as the DNA, and there are several possible reasons for the different phenotypes of these two mutations. Because the Asn-182-Asp protein is deficient in all functions of $\alpha 2$, it is possible that it is expressed poorly or is less stable than the wild type. A second possibility is that the change from Asn to Asp introduces an unfavorable negative charge into the DNA-protein interface that simply prevents the close approach of DNA and protein.

Experiments with Drosophila homeo domains have also revealed instances where mutations in DNA-binding residues do not necessarily eliminate biological functions. Schier and Gehring (1993) showed that a ftz to $b c d$ altered specificity mutant, created by a Gln-50-Lys change in $f t z$, provides efficient rescue of parasegments 8 and 14 but poorer rescue of other structures. Other mutations that compromise the strength of the ftz-DNA interaction show similar effects (Furukubo-Tokunaga et al. 1992).

These observations have several implications for the general understanding of homeo domain proteins. First, the study of homeo domain-DNA interactions in isolation, although of undeniable importance, may not necessarily reflect how these proteins act in vivo. For example, there appears to be little correlation between the behavior of many of the mutant $\alpha 2$ proteins in binding DNA alone when compared with binding DNA with al. In particular, the alteration of residues that, as seen to the X-ray structure, make specific contacts with DNA (Arg-135, Ser-181, Asn-182, and Arg-185) drastically reduces specific DNA binding by $\alpha 2$ alone but has little or no effect on the cooperative binding of $\alpha 2$ and al to DNA.

A second implication of these observations relates to the way homeo domain proteins may have evolved to participate in more than one regulatory circuit. It would seem that the specific DNA-binding residues of $\alpha 2$ are tailored for binding to asg operator with MCM1. On the basis of homologies in other fungi, it has been proposed that the $a 1 / \alpha 2$ circuit is of more ancient origin than the $\alpha 2 /$ MCM1 circuit (Johnson 1992). These ideas suggest a model where the al $/ \alpha 2$ circuit could be maintained while allowing the $\alpha 2$ homeo domain to undergo changes in DNA-binding specificity. That is, features of the al $/ \alpha 2$ circuit "free up" the DNA-binding residues of the $\alpha 2$ homeo domain for testing out and perhaps adopting new circuits without compromising the existing circuit. As many homeo domain proteins from other organisms are known to participate in multiple circuits, perhaps situations where homeo domains are buffered against mutational changes will be common. 


\section{Materials and methods}

Plasmids

Mutations in the $\alpha 2$ gene were constructed by site-directed oligonucleotide mutagenesis using the $d u t^{-}{ }^{-}$, ung ${ }^{-}$system /Smith 1985 ) in plasmid pAV99, a $\mathrm{P}_{\text {tac }}-\alpha 2$ vector with a single-stranded bacteriophage fl origin of replication (Mak and Johnson 1993). Oligonucleotides, used in the mutagenesis or construction of DNA-binding sites, were synthesized at the Biotechnology Resource Center at University of California San Francisco (UCSF) or on an ABI 392 synthesizer at the Waksman Institute, Rutgers University. Isolates of pAV115, a CEN LEU2 yeast plasmid with a 4.3-kb HindIII fragment that contains the entire MAT $\alpha$ locus and the specific site-directed mutations in the $\alpha 2$ gene, were constructed by cloning the 0.6-kb BglII-BamHI fragment from pAV99 containing the different mutations in the $\alpha 2$ gene. The construction of plasmids pAV99, pAV114 (a version of pAV115 without the MAT $\alpha$ fragment), and pAV115 was described in Mak and Johnson (1993). Plasmids pAV71 and pAV73, reporter vectors with and without the STE6 $\alpha 2 / \mathrm{MCM} 1$ DNA-binding site controlling expression of a CYC1-lacZ fusion, have been described elsewhere (Vershon et al. 1992). Plasmid pYJ103, which was used as a reporter plasmid for al/ $\alpha 2$-mediated repression, was constructed by inserting an oligonucleotide that contains a consensus al $/ \alpha 2$ binding site (TCATGTAATTAATTACATCA) into the SalI site in the CYC1-lacZ fusion promoter of pAV73.

\section{Yeast strains}

Most of the strains used in this study are congenic with strain EG123 (trp1 leu2 ura3 his4) and only vary at the MAT locus (Siliciano and Tatchell 1984). Wild-type MATa and MAT $\alpha$ strains are EG123 and 246.1.1, and the wild-type MATa/MAT $\alpha$ diploid used in these experiments is a product of a mating between these two strains. mats and mata2 cells are strains KT23 $\alpha 8$ and $23 \alpha 182$ (Tatchell et al. 1981) and were used as controls in the CYC1-lacZ repression and biological assays. The control MATa/mat 2 strain is from a mating of strains EG $123 \times 23 \alpha 182$. The construction of reporter strains containing integrated copies of CYC1-lacZ fusions with $\alpha 2 / \mathrm{MCM} 1$ or a1/a2 DNA-binding sites by $\mathrm{K}$. Komachi has been outlined in Mak and Johnson (1993).

Strain YV50 was constructed by integration at the MAT locus of a 4.3-kb HindIII MAT 1 , mata2::URA3 fragment in which the entire $\alpha 2$ gene has been replaced with URA3. This strain was used to integrate the $\alpha 2$ mutants into the MAT locus by the following procedure: Isolates of pAV115, containing different site-directed mutations in the $\alpha 2$ gene, were digested with Hin$\mathrm{dIII}$, and the linear 4.3-kb MAT $\alpha$ fragment was transformed into strain YV50 by the lithium acetate procedure (Ito et al. 1983). The transformed cells were grown on YEPD plates overnight at $30^{\circ} \mathrm{C}$ and then replated on $\mathrm{SD}+5$-fluoro-orotic acid $(5-\mathrm{FOA})$ plates to select for a Ura " phenotype (Sikorski and Boeke 1991). Resistant colonies were rescreened on SD + 5-FOA and SD-Ura plates to confirm the loss of URA3. Positive colonies were assayed by Southern blot for the presence of a $0.8-\mathrm{kb} B a m H I-B g I I I$ fragment, which is characteristic for the mutant $\alpha 2$ gene from pAV115. The following strains were constructed by this procedure: YJ08 (a reconstruction with wild-type $\alpha 2$ ), YJ01 (H3-3A), YJ02 (Arg-185-Met), YJ03 (Ser-181-Ile), YJ04 (Leu-196-Ser), YJ05 (Arg-135-Ala), YJ06 (Lys-188-Ile), and Yj07 (Ser-181-Gln).

Because strains containing integrated copies of the $\alpha 2 \mathrm{mu}$ tants will not mate properly with MATa cells, diploid strains containing the $\alpha 2$ mutants were constructed by transforming these strains with a wild-type MAT $\alpha$ URA3 $2 \mu$ plasmid and mating the transformants with a MATa strain containing a TRP1 ARS plasmid. Diploids were selected on SD-Ura-Trp plates-the plasmids were lost by growing the cells nonselectively on YEPD-and then screened for colonies that were unable to grow in the absence of uracil and tryptophan. The presence of the $\alpha 2$ mutation in the resulting strains was verified by Southern blot for the presence of the $\alpha 2$ BamHI-BglII fragment

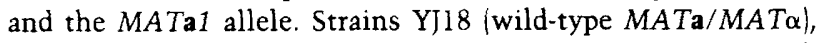
YJ11 (MATa/mata2 H3-3A), YJ12 (MATa/mat $\alpha 2$ Arg-185-Met), YJ13 (MATa/mata2 Ser-181-Ile), YJ14 (MATa/mata2 Leu-196Ser), YJ15 (MATa/mata2 Arg-135-Ala), YJ16 (MATa/mata2 Lys-188-Ile), and YI17 (MATa/mata2 Ser-181-Gln) were constructed by the above procedure.

Yeast media used in these experiments are described in Sherman et al. (1979). Halo, mating type, and sporulation tests were performed using the same procedures and strains as described in Mak and Johnson (1993).

\section{Protein purification}

Full-length wild-type $\alpha 2$ (residues 1-210) was purified from strain SY903.1 containing plasmid pDS-1, a $\mathrm{P}_{\mathrm{tac}}-\alpha 2$ expression vector, by a modified version of the procedure in Sauer et al. (1988) as described in Mak and Johnson (1993). Mutant $\alpha 2$ proteins were purified by the same procedure from transformants of strain SY903.1 with pAV100 containing mutations in the $\alpha 2$ gene. Plasmid pAV100, a $\mathrm{P}_{\mathrm{tac}}-\alpha 2$ vector, was constructed by removing a 1.4-kb BamHI fragment from pAV99 that is $200 \mathrm{bp}$ past the termination codon of the $\alpha 2$ gene. We have observed that removal of this fragment allows greater expression of the $\alpha 2$ protein. Purified mutant and wild-type $\alpha 2$ proteins were dialyzed into $\mathrm{S}+500$ buffer $(50 \mathrm{~mm}$ Tris- $\mathrm{HCl}$ at $\mathrm{pH} 8.0,1 \mathrm{~mm}$ EDTA, $10 \mathrm{~mm} \beta$-mercaptoethanol, $500 \mathrm{~mm} \mathrm{NaCl}$ ). The concentrations of the purified proteins were determined by measuring the absorbance at $280 \mathrm{~nm}$ and using the theoretical extinction coefficient of OD 0.60 per $\mathrm{mg} / \mathrm{ml}$ for full-length $\alpha 2$. The relative purities and concentrations of the different proteins were verified by Coomassie staining of SDS gels of the samples. a1 Protein was purified from bacteria transformed with a $\mathrm{P}_{\mathrm{T} 7}-\mathbf{a l}$ ex pression vector and was a gift from C. Goutte (UCSF, CA). The $\mathrm{MCMl}_{1-97}$ protein used in the DNA-binding experiments was a fragment of the intact protein (residues 1-97) that contains the DNA-binding domain and was purified from bacteria that contain pAV154 as described in Vershon and Johnson (1993).

\section{DNA-binding experiments}

The labeled wild-type $\alpha 2 / \mathrm{MCM} 1$ (from the STE6 promoter) and a $/ \alpha 2$ (from the $M F \alpha 1$ promoter) sites used in the gel mobility shift experiments were generated by isolating the 86 - and $73-$ bp fragments from an EcoRI and HindIII restriction digest of $\mathrm{pCKl}$ and pCG25, respectively (Goutte and Johnson 1988; Keleher et al. 1988), and filling the $5^{\prime}$ overhangs with ${ }^{32} \mathrm{P}$ using Klenow polymerase. Mobility retardation assays were performed in 20 mM Tris (pH 8.0), $1 \mathrm{~mm}$ EDTA, $5 \mathrm{mM} \mathrm{MgCl}_{2}, 10 \mathrm{~m} / \mathrm{ml}$ of BSA (fraction V), $5 \%$ glycerol, $0.1 \% \mathrm{NP}-40$, and $10 \mu \mathrm{g} / \mathrm{ml}$ of sheared salmon sperm DNA. Protein dilutions were made in $50 \mathrm{~mm}$ Tris (pH 8.0), $1 \mathrm{~mm}$ EDTA, $500 \mathrm{~mm} \mathrm{NaCl}, 10 \mathrm{~mm}$ 2-mercaptoethanol, and $10 \mathrm{mg} / \mathrm{ml}$ of BSA. Five microliters of $\alpha 2$ and $5 \mu \mathrm{l}$ of MCMl, al, or protein dilution buffer were added to $40 \mu \mathrm{l}$ of end-labeled operator fragment diluted in assay buffer, so that the final $\mathrm{NaCl}$ concentration was $100 \mathrm{~mm}$. Reactions were incubated at room temperature for at least $1.5 \mathrm{hr}$ and one-half of the reaction was loaded onto $6 \%$ polyacrylamide gel and electrophoresed at 200 
$\mathrm{V}$ for $2 \mathrm{hr}$. Gels were dried and scanned on a Molecular Dynamics PhosphorImager.

\section{Acknowledgments}

We thank Caroline Goutte for providing purified al protein and Kelly Komachi for the yeast strains that contain integrated versions of CYC1-lacZ promoter constructs. This work was supported by grants from the National Institutes of Health to A.K.V. (GM49265) and A.D.J. (GM37049). Y.J. was a recipient of the New Jersey Cell and Molecular Biology Fellowship.

The publication costs of this article were defrayed in part by payment of page charges. This article must therefore be hereby marked "advertisement" in accordance with 18 USC section 1734 solely to indicate this fact.

\section{References}

Ades, S.E. and R.T. Sauer. 1994. Differential DNA-binding specificity of the engrailed homeodomain: The role of residue 50 . Biochemistry 33: 9187-9194.

Ammerer, G. 1990. Identification, purification, and cloning of a polypeptide (PRTF/GRM) that binds to mating-specific promoter elements in yeast. Genes \& Dev. 4: 299-312.

Billeter, M., Y.Q. Qian, G. Otting, M. Muller, W. Gehring, and K. Wuthrich. 1993. Determination of the nuclear magnetic resonance solution structure of an Antennapedia homeodomain-DNA complex. I. Mol. Biol. 234: 1084-1097.

Ceska, T.A., M. Lamers, P. Monaci, A. Nicosia, R. Courtese, and D. Suck. 1993. The X-ray structure of an atypical homeodomain present in the rat liver transcription factor LFB1/ HNF1 and implications for DNA binding. EMBO $/$. 12: $1805-1810$.

Dranginis, A.M. 1990. Binding of yeast $\mathbf{a} 1$ and $\alpha 2$ as a heterodimer to the operator DNA of a haploid-specific gene. Nature 347: 682-685.

Fields, S. and I. Herskowitz. 1985. The yeast STE12 product is required for expression of two sets of cell-type-specific genes. Cell 42: 923-930.

Furukubo-Tokunaga, K., M. Muller, M. Affolter, L. Pick, U. Kloter, and W.J. Gehring. 1992. In vivo analysis of the helixturn-helix motif of the fushi tarazu homeo domain of Drosophila melanogaster. Genes \& Dev. 6: 1082-1096.

Gehring, W.J., Y.Q. Qian, M. Billeter, K. Furukubo-Tokunaga, A.F. Schier, D. Resendez-Perez, M. Affolter, G. Otting, and K. Wüthrich. 1994. Homeodomain-DNA recognition. Cell 78: 211-223.

Goutte, C. and A.D. Johnson. 1988. al protein alters the DNA binding specificity of $\alpha 2$ repressor. Cell 52: 875-882.

- 1993. Yeast al and $\alpha 2$ homoeodomain proteins form a DNA-binding activity with properties distinct from those of either protein. I. Mol. Biol. 233: 359-371.

- 1994. Recognition of a DNA operator by a dimer composed of two different homeodomain proteins. EMBO $/$. 13: 1434-1442.

Hall, M.N. and A.D. Johnson. 1987. homeodomain of the yeast repressor $\alpha 2$ is a sequence-specific DNA-binding domain but is not sufficient for repression. Science 237: 1007-1012.

Hanes, S.D. and R. Brent. 1989. DNA specificity of the Bicoid activator protein is determined by homeodomain recognition helix residue 9. Cell 57: 1275-1283.

Hayashi, S. and M.P. Scott. 1990. What determines the specificity of action of Drosophila homeodomain proteins? Cell 63: 883-894.

Ito, H., Y. Kukada, K. Murata, and A. Kimura. 1983. Transfor- mation of intact yeast cells treated with alkali ions. J. Bacteriol. 153: 163-168.

Johnson, A.D. 1992. A combinatorial regulatory circuit in budding yeast. In Transcriptional regulation (ed. K. Yamamoto and S. McKnight|, pp. 975-1006. Cold Spring Harbor Laboratory Press, Cold Spring Harbor, New York.

Johnson, A.D. and I. Herskowitz. 1985. A repressor (MAT $\alpha 2$ product) and operator control expression of a set of cell type specific genes in yeast. Cell 42: 237-247.

Keleher, C.A., C. Goutte, and A.D. Johnson. 1988. The yeast cell-type repressor $\alpha 2$ acts cooperatively with a non-celltype-specific protein. Cell 53: 927-936.

Kissinger, C.R., B. Liu, E. Martin-Blanco, T.B. Kornberg, and C.O. Pabo. 1990. Crystal structure of an engrailed homeodomain-DNA complex at 2.8 A resolution: A framework for understanding homeodomain-DNA interactions. Cell 63: $579-590$.

Klemm, J.D., M.A. Rould, R. Aurora, W. Herr, and C.O. Pabo. 1994. Crystal structure of the Oct-1 POU domain bound to an octamer site: DNA recognition with tethered DNA-binding modules. Cell 77: 21-32.

Laughon, A. and M.P. Scott. 1984. The sequence of a Drosophila segmentation gene: Protein structure homology with DNA binding proteins. Nature 310: 25-30.

Leiting, B., R. De Francesco, L. Tomei, R. Courtese, G. Otting, and K. Wuthrich. 1993. The three-dimensional NMR-solution structure of the polypeptide fragment 195-286 of the LBF/HNFI transcription factor from rat liver comprises a non-classical homeo domain. EMBO /. 12: 1797-1803.

Mak, A. and A.D. Johnson. 1993. The carboxy-terminal tail of the homeo domain protein $\alpha 2$ is required for function with a second homeo domain protein. Genes \& Dev. 7: 1862-1870.

McGinnis, W., M.S. Levine, E. Hafen, A. Kuroiwa, and W.J. Gehring. 1984a. A conserved DNA sequence in homeotic genes of the Drosophila Antennapedia and bithorax complexes. Nature 308: 428-433.

McGinnis, W., R.L Garber, J. Wirz, A. Kuroiwa, and W.J. Gehring. 1984b. A homologous protein-coding sequence in Drosophila homeotic genes and its conservation in other metazoans. Cell 37: 403-408.

Miller, A.M., V.L. MacKay, and K.A. Nasmyth. 1985. Identification and comparison of two sequence elements that confer cell-type specific transcription in yeast. Nature 314: 598603.

Mitchell, A.P. and I. Herskowitz. 1986. Activation of meiosis and sporulation by repression of the RME1 product in yeast. Nature 319: 738-742.

Otting, G., Y.Q. Qian, M. Billeter, M. Mueller, M. Affolter, W.J. Gehring, and K. Wuthrich. 1990. Protein-DNA contacts in the structure of a homeodomain-DNA complex determined by nuclear magnetic resonance spectroscopy in solution. EMBO I. 9: 3085-3092.

Passmore, S., R. Elble, and B.-K. Tye. 1989. A protein involved in minichromosome maintenance in yeast binds a transcriptional enhancer conserved in eukaryotes. Genes \& Dev. 3: 921-935.

Phillips, C.L., A.K. Vershon, A.D. Johnson, and F.W. Dahlquist. 1991. Secondary structure of the homeodomain of yeast $\alpha 2$ repressor determined by NMR spectroscopy. Genes \& Dev. 5: 764-772.

Porter S.D. and M. Smith. 1986. homeo domain homology in yeast $M A T \alpha 2$ is essential for repressor activity. Nature 320: 766-768.

Qian, Y.Q., M. Billeter, G. Otting, M. Muller, W.J. Gehring, and K. Wuthrich. 1989. The structure of the Antennapedia homeodomain determined by NMR spectroscopy in solution: 
Vershon et al.

Comparison with prokaryotic repressors. Cell 59: 573-580.

Sauer, R.T., D.L. Smith, and A.D. Johnson. 1988. Flexibility of the yeast $\alpha 2$ repressor enables it to occupy the ends of its operator, leaving the center free. Genes \& Dev. 2: 807-816.

Schier, A.F. and W.J. Gehring. 1993. Functional specificity of the homeodomain protein fushi tarazu: The role of DNAbinding specificity in vivo. Proc. Natl. Acad. Sci. 90: 14501454.

Scott, M.P., J.W. Tamkun, and G.W. Hartzell. 1989. The structure and function of the homeodomain. Biochem. Biophys. Acta. 989: 25-48.

Shepherd, J.C.W., W. McGinnis, A.E. Carrasco, E.M. De Robertis, and W.J. Gehring. 1984. Fly and frog homeo-domains show homologies with yeast mating type regulatory proteins. Nature 310: 70-71.

Sherman, F., G.R. Fink, and C.W. Lawrence. 1979. Methods in yeast genetics. Cold Spring Harbor Laboratory, Cold Spring Harbor, New York.

Sikorski, R.S. and J.D. Boeke. 1991. In vitro mutagenesis and plasmid shuffling: From cloned gene to mutant yeast. Methods Enzymol. 194: 302-318.

Siliciano, P.G. and K. Tatchell. 1984. Transcription and regulatory signals at the mating type locus in yeast. Cell 37: 969978.

Smith, D.L. and A.D. Johnson. 1992. A molecular mechanism for combinatorial control in yeast: MCMl protein sets the spacing and orientation of the homeodomain of an $\alpha 2$ dimer. Cell 68: 133-142.

- 1994. Operator-constitutive mutations in a DNA sequence recognized by a yeast homeodomain. EMBO $/$. 13: $2378-2387$.

Smith, M. 1985. In vitro mutagenesis. Annu. Rev. Genet. 19: 423-462.

Sprague, G.F. 1991. Assay of yeast mating reaction. Methods Enzymol. 147: 357-372.

Strathern, J., J. Hicks, and I. Herskowitz. 1981. Control of cell type in yeast by the mating type locus: The $\alpha 1-\alpha 2$ hypothesis. I. Mol. Biol. 147: 357-372.

Strathern, J., B. Shafer, J. Hicks, and C. McGill. 1988. a/ $\alpha$-Specific repression by MAT $\alpha 2$. Genetics 120: 75-81.

Tatchell, K., K.A. Nasmyth, and B.D. Hall. 1981. In vitro mutation analysis of the mating-type locus in yeast. Cell 27: 25-35.

Treisman, J., P. Gonczy, M. Vashishtha, E. Harris, and C. Desplan. 1989. A single amino acid can determine the DNA binding specificity of homeodomain proteins. Cell 59: 553562.

Vershon, A.K. and A.D. Johnson. 1993. A short, disordered protein region mediates interactions between the homeodomain of the yeast a 2 protein and the $\mathrm{MCM} 1$ protein. Cell 72: 105-112.

Vershon, A.K., N.M. Hollingsworth, and A.D. Johnson. 1992. Meiotic induction of yeast HOP1 gene is controlled by positive and negative regulatory sites. Mol. Cell. Biol. 12: 37063714.

Wolberger, C., A.K. Vershon, B. Liu, A.D. Johnson, and C.O. Pabo. 1991. Crystal structure of a MAT $\alpha 2$ homeodomainoperator complex suggests a general model for homeodomain-DNA interactions. Cell 67: 517-528.

Wuthrich, K. and W. Gehring. 1992. Transcriptional regulation by homeodomain proteins: Structural, functional, and genetic aspects. In Transcriptional regulation led. $\mathrm{K}$. Yamamoto and S. McKnight), pp. 535-566. Cold Spring Harbor Laboratory Press, Cold Spring Harbor, New York. 


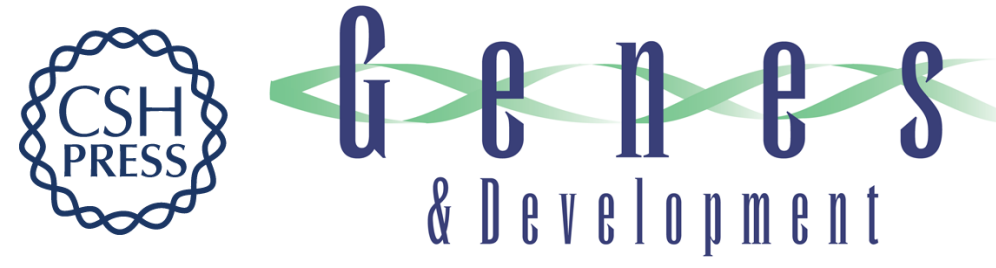

\section{A homeo domain protein lacking specific side chains of helix 3 can still bind DNA and direct transcriptional repression.}

A K Vershon, $Y$ Jin and A D Johnson

Genes Dev. 1995, 9:

Access the most recent version at doi:10.1101/gad.9.2.182

References This article cites 48 articles, 11 of which can be accessed free at:

http://genesdev.cshlp.org/content/9/2/182.full.html\#ref-list-1

License

Email Alerting

Service right corner of the article or click here.

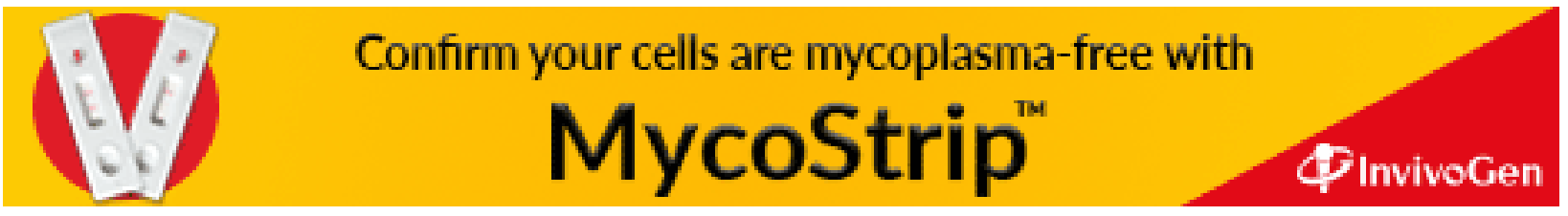

